\title{
Kinetics of the Polyphenolic Content and Radical Scavenging Capacity in Olives through On-Tree Ripening
}

\author{
Irene Gouvinhas, ${ }^{1}$ Raúl Domínguez-Perles, ${ }^{1}$ Amadeo Gironés-Vilaplana, \\ Teresa Carvalho, ${ }^{3}$ Nelson Machado, ${ }^{1}$ and Ana Barros ${ }^{1}$ \\ ${ }^{1}$ Centre for the Research and Technology of Agro-Environmental and Biological Sciences, University of Trás-os-Montes e Alto Douro, \\ (CITAB-UTAD), Quinta de Prados, 5000-801 Vila Real, Portugal \\ ${ }^{2}$ Department of Food Technology, EPSO, Miguel Hernández University, Ctra. Beniel km 3.2, Orihuela, 03312 Alicante, Spain \\ ${ }^{3}$ National Institute for Agricultural and Veterinary Research (INIAV I.P.), Elvas, Portugal
}

Correspondence should be addressed to Irene Gouvinhas; igouvinhas@utad.pt and Raúl Domínguez-Perles; rdperles@utad.pt

Received 8 September 2016; Accepted 1 December 2016; Published 2 January 2017

Academic Editor: Sevgi Kolaylı

Copyright (C) 2017 Irene Gouvinhas et al. This is an open access article distributed under the Creative Commons Attribution License, which permits unrestricted use, distribution, and reproduction in any medium, provided the original work is properly cited.

Olive fruits, as well as their corresponding oil, represent an interesting source of phytochemicals, mainly phenolic compounds, which arise as secondary metabolites, resulting from the plant's response to biotic and abiotic stresses. Therefore, olive fruits from three distinct cultivars ("Cobrançosa," "Galega Vulgar," and "Picual") grown in Portugal and displaying different degree of resistance to biotic and abiotic stresses have been studied in relation to the concentration of total phenolic compounds, orthodiphenols and flavonoids, besides antioxidant capacity (DPPH, ABTS, FRAP, and $\mathrm{ORAC}_{\mathrm{FL}}$ ), in three maturation stages and two distinct harvest seasons (2012-2013). Generally, a decrease of all phenolic contents throughout the maturation stages has been observed, while, concerning cultivar, green olives of "Cobrançosa" showed the highest values for all contents assessed, denoting a strong influence of the genetic background. The same trend has not been observed regarding antioxidant activity, since Cobrançosa and Galega Vulgar cultivars presented the highest values only for the DPPH and $\mathrm{ORAC}_{\mathrm{FL}}$ assays. Moreover, multivariate analyses pointed to the preponderance of the cultivars' phenolic composition in the semiripe stage for the resistance to biotic stress, with "Galega" the most susceptible cultivar, presenting the lowest contents at this maturation stage, whereas "Picual" displayed the most pronounced phytochemical response.

\section{Introduction}

Nowadays, consumers are becoming increasingly aware of the relevance of balanced diets to the maintenance of the health status, selectively introducing foodstuffs as response to relevant health claims assigned to these products. In this sense, the consumers perception is supported by several epidemiological studies performed, which pointed out the intake of olives (Olea europaea L.) and olive oils as being responsible for the reduction of the incidence and prevalence of cardiovascular diseases, certain types of cancer, and agingrelated pathologies $[1,2]$. Therefore, the subsequent growing demand of healthy agrofood products by consumers has prompted the increase of the world production of olives addressed to oil production of 435,009 to 702,140 tons from
2010 to 2015, at which processing allowed augmenting the olive oil production from 625,503 to $1,190,523 \mathrm{hL}$ [3]. From the evolution of data on olives' production and transformation, it can be foreseen as an even higher potential, desirable for the local industry, in order to reduce the dependence on olive oil imports (which in Portugal reached, in 2014, almost 113,152 tons) and thus for improving the trade balance [3].

The health benefits attributed to the dietary consumption of olive oils have been traditionally assigned to their high content in polyunsaturated fatty acids, especially concerning oleic acid and, in a lower extent, to their features as sources of bioactive polyphenols (flavonoids and nonflavonoids), the first group representing up to $3.0 \%$ of fresh pulp weight [4]. Nonetheless, despite the valuable composition of olives and olive oils regarding biologically active compounds with 
health attributions, their relative concentration in these food matrices is closely dependent on several factors, namely, agroclimatic conditions, cultivar, and ripening stages, among others. In this connection, the development of further evaluations of the isolated effect of some of these factors remains a pertinent issue [5]. So, there is a challenge to enhance the industrial transformation of "Cobrançosa," "Galega," and "Picual" olives, which display very attractive sensorial properties and potential interest for industry and consumers [6].

From these three major cultivars exploited in Portugal, although the resistance to abiotic stress featured by "Galega" allowed its extensive implantation in Portugal, this cultivar is rather vulnerable to fungal infectious diseases, such as Colletotrichum acutatum (anthracnose) an endemic olive tree disease in Portugal [7]. On the other hand, the other widely implemented cultivars in Portugal, namely, "Cobrançosa" and "Picual," are characterized by a moderate susceptibility and tolerance to this fungal infection, respectively [8]. The differentiated susceptibility of these cultivars to anthracnose is strongly influenced by the ripening stage, since full-ripe olives are rather susceptible, which turns the evaluation of these three cultivars, regarding the (poly)phenolic content, into a preeminent issue $[9,10]$.

Therefore, the present study envisages the assessment of polyphenolic composition (total phenolics, flavonoids, and orthodiphenols) of olives from three distinct cultivars, displaying different susceptibilities to anthracnose ("Cobrançosa," "Galega," and "Picual”) and concerning their antioxidant activity, which was evaluated through distinct methods (DPPH, ABTS, FRAP, and $\mathrm{ORAC}_{\mathrm{FL}}$ ). Furthermore, the variation of these parameters throughout the on-tree ripening process (green, semi-ripe, and ripe) was also monitored, in order to gain a further insight into the relationship between the (poly)phenolic composition and the differentiated resistances to this fungal disease, according to cultivar and maturation stage. This approach, comprising both the phytochemical evaluation and the chemometric analyses developed, provided noticeable information on the predictive value of the (poly)phenolic composition on the optimal harvest time.

\section{Material and Methods}

2.1. Reagents. The compounds 2,2-diphenyl-1-picrylhydrazyl radical (DPPH ${ }^{\bullet}$ ), 2,2-azino-bis(3-ethylbenzothiazoline-6-sulphonic acid)diammonium salt $\left(\mathrm{ABTS}^{\bullet+}\right)$, 2,4,6-tripyridyl$\mathrm{S}^{\prime}$-triazine (TPTZ), ferric chloride hexahydrate, fluorescein (free acid), 2,2'-azobis(2-methylpropionamidine) dihydrochloride $(\mathrm{APPH})$, monobasic sodium phosphate, dibasic sodium phosphate, phenazine methosulphate (PMS), nitrotetrazolium blue chloride (NBT), trizma ${ }^{\circledR}$-hydrochloride, and potassium phosphate were obtained from SigmaAldrich (Steinheim, Germany). Additionally, 6-hydroxy2,5,7,8-tetramethylchroman-2-carboxylic acid (Trolox) and magnesium chloride hexahydrate were purchased from Fluka Chemika (Neu-Ulm, Switzerland). Folin-Ciocalteu's reagent, 3,4,5-trihydroxybenzoic acid (gallic acid), and acetic acid, both extra pure (>99\%), were purchased from Panreac (Panreac Química S.L.U., Barcelona, Spain). Sodium nitrate, aluminium chloride, and sodium carbonate, all extra pure (>99\%), were acquired from Merck (Merck, Darmstadt, Germany). Sodium molybdate (99.5\%) was purchased from Chem-Lab (Chem-Lab NV, Zedelgem, Belgium). Ultrapure water was obtained using a Millipore water purification system.

2.2. Plant Material. The present work was carried out on olive fruits from three cultivars ("Cobrançosa," "Galega," and "Picual"). Olives were obtained from a certified olive orchard, at the National Plant Breeding Station in Elvas (Portugal) during the crop seasons 2012 and 2013. The relative humidity registered in the growing area averaged $67.8 / 70.4 \%$ and the average air temperature was $16.69 / 17.08^{\circ} \mathrm{C}$ during the seasons 2012/2013 (Table 1).

Only healthy olive drupes, without any kind of infection or physical damage, were collected from ten different trees of comparable age and vigour, evenly spaced between them, within the same growing area. Thus, differences due to weather conditions, agricultural practices, and geographical locations can be excluded. Olives were handpicked at three ripening stages (green, semiripe, and ripe). The harvesting dates and the ripening index (RI) are showed in Table 2. For the assessment of the RI, the harvested olives were evaluated according to the skin and pulp colour, following the criteria previously described in the literature [11]. The RI values considered ranged from 0 (100\% intense green skin) to 7 (100\% purple flesh and black skin).

After harvesting, olive fruits were immediately transported to the laboratory and stored at $-20^{\circ} \mathrm{C}$ until processing and analysis.

2.3. Preparation of Extracts for Analysis. Olive samples (5.0 g) were macerated with $50.0 \mathrm{~mL}$ of a mixture of $\mathrm{MeOH} / \mathrm{H}_{2} \mathrm{O}$ $(50: 50, \mathrm{v} / \mathrm{v})$ and incubated at room temperature for $30 \mathrm{~min}$. Then, supernatants were collected and the extractions were repeated three times. The liquid phase was filtered and subsequently centrifuged at $9000 \mathrm{rpm}$ for $10 \mathrm{~min}$. To remove the fat phase, the mixture was washed twice with hexane $(50.0 \mathrm{~mL})$, using a separating funnel and the organic phase containing fatty acids was discarded. Extract volume obtained from each sample was made up to $200.0 \mathrm{~mL}$ in a volumetric flask with $\mathrm{MeOH} / \mathrm{H}_{2} \mathrm{O}(50: 50, \mathrm{v} / \mathrm{v})$ [12]. Three replicates $(n=$ $3)$ per sample were evaluated.

2.4. Total Phenolics Content. The content of total phenolic compounds of olive's extracts was determined using FolinCiocalteu reagent, with gallic acid as standard according to the method previously described [13]. Briefly, one millilitre of diluted samples was mixed with $500 \mu \mathrm{L}$ of Folin-Ciocalteu reagent, $2.0 \mathrm{~mL}$ of $7.5 \%$ sodium carbonate solution (w/v), and $6.5 \mathrm{~mL}$ of water. The mixture was shaken gently and, after $30 \mathrm{~min}$ of reaction at $70^{\circ} \mathrm{C}$, the absorbance was measured at $750 \mathrm{~nm}$ by spectrophotometer (Spectronic Genesys ${ }^{\mathrm{TM}} 20$ Visible Spectrophotometer, Thermo Fisher Scientific). The content of total phenolics was expressed as milligrams of 


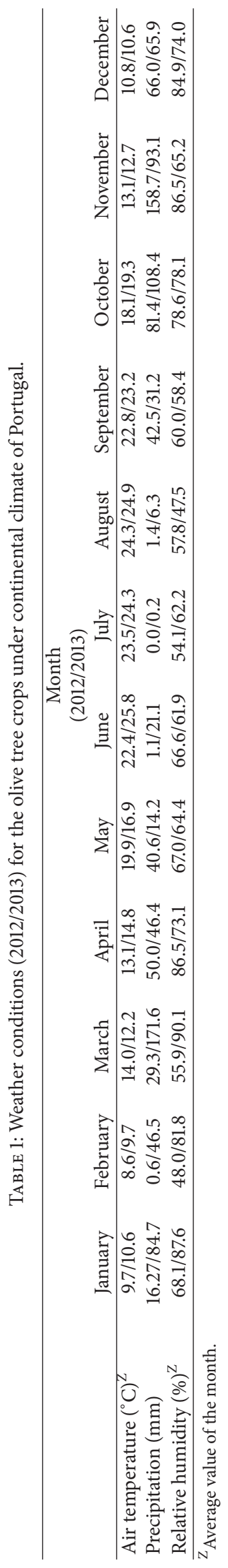


TABLE 2: Schedule for olives sampling.

\begin{tabular}{|c|c|c|c|c|}
\hline Cultivar & Maturity stage & Sample code & Harvest date & $\mathrm{RI}^{\mathrm{Z}}$ \\
\hline \multirow{6}{*}{ "Cobrançosa" } & Green & Cob G & $02 / 10 / 2012$ & 1.14 \\
\hline & Semiripe & Cob SR & $12 / 10 / 2012$ & 2.10 \\
\hline & Ripe & Cob R & 08/11/2012 & 4.56 \\
\hline & Green & Cob G & $17 / 10 / 2013$ & 1.46 \\
\hline & Semiripe & Cob SR & 01/11/2013 & 3.82 \\
\hline & Ripe & Cob R & $13 / 11 / 2013$ & 4.78 \\
\hline \multirow{6}{*}{ "Galega" } & Green & Gal G & $02 / 10 / 2012$ & 1.22 \\
\hline & Semiripe & Gal SR & $12 / 10 / 2012$ & 2.44 \\
\hline & Ripe & Gal R & 08/11/2012 & 4.98 \\
\hline & Green & Gal G & $08 / 10 / 2013$ & 1.38 \\
\hline & Semiripe & Gal SR & $17 / 10 / 2013$ & 3.04 \\
\hline & Ripe & Gal R & $12 / 11 / 2013$ & 4.76 \\
\hline \multirow{6}{*}{ "Picual" } & Green & Pic G & $02 / 10 / 2012$ & 0.76 \\
\hline & Semiripe & Pic SR & $12 / 10 / 2012$ & 1.98 \\
\hline & Ripe & Pic R & 08/11/2012 & 4.24 \\
\hline & Green & Pic G & $17 / 10 / 2013$ & 0.84 \\
\hline & Semiripe & Pic SR & $01 / 11 / 2013$ & 2.88 \\
\hline & Ripe & Pic R & $13 / 11 / 2013$ & 4.9 \\
\hline
\end{tabular}

Ripening index.

gallic acid equivalents per gram of olive fruits dry weight (mg GAE g $\left.{ }^{-1} \mathrm{dw}\right)$.

2.5. Orthodiphenol Content. The content of orthodiphenols was assessed as previously described by Mateos et al. [14]. One millilitre of $5.0 \%$ sodium molybdate $(\mathrm{w} / \mathrm{v})$ in $50.0 \%$ hydromethanol (v/v) was added to $4.0 \mathrm{~mL}$ of the diluted sample or gallic acid. After $15 \mathrm{~min}$., the absorbance was measured by $370 \mathrm{~nm}$ by spectrophotometer (Spectronic Genesys ${ }^{\mathrm{TM}} 20$ Visible Spectrophotometer). The content of orthodiphenols was expressed as mg GAE $\mathrm{g}^{-1} \mathrm{dw}$.

2.6. Flavonoids Content. Flavonoids content was determined by the colorimetric assay described by Zhishen et al. [15]. Briefly, $0.5 \mathrm{~mL}$ of diluted sample was mixed with $150 \mu \mathrm{L}$ of $0.50 \mathrm{M} \mathrm{NaNO}_{2}$. After $5 \mathrm{~min}, 150 \mu \mathrm{L}$ of $0.75 \mathrm{M} \mathrm{AlCl}_{3}$ was added. The mixture was stirred and allowed to react for $6 \mathrm{~min}$. Afterwards, $1.0 \mathrm{~mL}$ of $1.00 \mathrm{M} \mathrm{NaOH}$ was added and the absorbance was measured at $510 \mathrm{~nm}$ using spectrophotometer (Spectronic Genesys ${ }^{\mathrm{TM}} 20$ Visible Spectrophotometer). The results were expressed as milligrams of catechin per gram of olive fruits dry weight ( $\mathrm{mg} \mathrm{CAT} \mathrm{g}^{-1} \mathrm{dw}$ ).

2.7. Antioxidant Activity. The free radical scavenging activity was determined by DPPH and ABTS methods adapted to a microscale, according to the procedure described by Mena et al. [16], by measuring the variation in absorbance at $515 \mathrm{~nm}$ after $50 \mathrm{~min}$ of reaction with the radical for $\mathrm{DPPH}^{\circ}$ and at $414 \mathrm{~nm}$ after $50 \mathrm{~min}$ for $\mathrm{ABTS}^{\circ+}$. The reducing capacity was determined using the FRAP method, through the measurement of the variation in absorbance at $593 \mathrm{~nm}$ after
40 min of reaction. The assays were performed using 96well microplates (Nunc, Roskilde, Denmark) and an Infinite M200 microplate reader (Tecan, Grödig, Austria). All the reactions were started by adding $2 \mu \mathrm{L}$ of the corresponding diluted sample to the well containing the stock solution $(250 \mu \mathrm{L})$. The final volume of the assay was $252 \mu \mathrm{L}$. The antioxidant activity was also determined using the $\mathrm{ORAC}_{\mathrm{FL}}$ assay, according to the method developed by Ou et al. [17]. The results were expressed as $\mathrm{mM}$ Trolox $\mathrm{g}^{-1}$ of olive fruits dry weight (mM Trolox $\left.\mathrm{g}^{-1} \mathrm{dw}\right)$.

2.8. Statistical Analysis. The results are presented as mean values \pm standard deviation $(n=3)$. All the data were subjected to analysis of variance (ANOVA) and a multiple range test (Tukey's test), using IBM SPSS statistics 21.0 software (SPSS Inc., Chicago, IL, USA). Differences between means were considered different at $p<0.05$. Partial Least SquaresRegression (PLS-R) was carried out resorting to Wold's iteration, using the OriginPro 9.1 software package (Origin Lab Corporation, Northampton, MA, USA). The maturity stage (green, semiripe, and ripe) was defined as dependent variable, whilst all the parameters assessed (total phenols, orthodiphenols, flavonoids, and radical scavenging activity measurements) represented the independent variables, with the loadings corresponding to each one of these parameters being extracted for all the factors retrieved.

\section{Results and Discussion}

3.1. (Poly)phenolic Composition of Olive Fruits. The assessment of the content of total phenols in olives at different on-tree ripening stages evidenced significant differences in 
TABLE 3: Content of total phenolics and orthodiphenols ( $\mathrm{mg} \mathrm{GAE}^{-1}$ dry weight $(\mathrm{dw})$ ) and content of flavonoids (mg CAT g $\left.\mathrm{m}^{-1} \mathrm{dw}\right)$ in olives at different on-tree maturation stages (green, semiripe, and ripe).

\begin{tabular}{|c|c|c|c|c|}
\hline Cultivar & On-tree ripening stage & Total phenolics & Orthodiphenols & Flavonoids \\
\hline \multirow{7}{*}{ "Cobrançosa" } & Green, 2012 & $50.11 \pm 2.10 \mathrm{~B}^{\mathrm{Z}} \mathrm{c}^{\mathrm{Y}}$ & $74.89 \pm 1.97 \mathrm{C} \mathrm{b}$ & $45.25 \pm 1.65 \mathrm{~B} \mathrm{C}$ \\
\hline & Green, 2013 & $47.05 \pm 4.88 \mathrm{~B} \mathrm{c}$ & $57.62 \pm 2.68 \mathrm{~B} \mathrm{C}$ & $40.78 \pm 2.65 \mathrm{~B} \mathrm{c}$ \\
\hline & Semiripe, 2012 & $35.27 \pm 0.93 \mathrm{~A} \mathrm{a}$ & $40.95 \pm 3.20 \mathrm{~A} \mathrm{a}$ & $27.16 \pm 2.63 \mathrm{Ac}$ \\
\hline & Semiripe, 2013 & $31.42 \pm 3.89 \mathrm{~A} \mathrm{a}$ & $49.00 \pm 6.74 \mathrm{AB} \mathrm{b}$ & $26.92 \pm 3.24 \mathrm{~A} \mathrm{~b}$ \\
\hline & Ripe, 2012 & $34.65 \pm 0.87 \mathrm{~A} \mathrm{a}$ & $49.50 \pm 2.07 \mathrm{AB} \mathrm{a}$ & $30.44 \pm 0.55 \mathrm{~A} \mathrm{~b}$ \\
\hline & Ripe, 2013 & $33.89 \pm 1.40 \mathrm{~A} \mathrm{~b}$ & $54.95 \pm 3.86 \mathrm{~B} \mathrm{~b}$ & $26.88 \pm 0.69 \mathrm{~A} \mathrm{~b}$ \\
\hline & ANOVA $p$ value & $* * *^{\mathrm{X}}$ & $* * *$ & $* * *$ \\
\hline \multirow{7}{*}{ "Galega Vulgar" } & Green, 2012 & $36.99 \pm 0.77 \mathrm{C} \mathrm{a}$ & $56.43 \pm 3.04 \mathrm{C} \mathrm{a}$ & $30.39 \pm 2.63 \mathrm{C} \mathrm{a}$ \\
\hline & Green, 2013 & $38.14 \pm 1.81 \mathrm{Cb}$ & $36.90 \pm 3.15 \mathrm{~A} \mathrm{a}$ & $34.19 \pm 2.60 \mathrm{Cb}$ \\
\hline & Semiripe, 2012 & $30.79 \pm 1.26 \mathrm{BC} \mathrm{a}$ & $39.20 \pm 1.05 \mathrm{~A} \mathrm{a}$ & $23.79 \pm 0.60 \mathrm{~B} \mathrm{ab}$ \\
\hline & Semiripe, 2013 & $25.71 \pm 1.70 \mathrm{~A} \mathrm{a}$ & $33.96 \pm 2.44 \mathrm{~A} \mathrm{a}$ & $18.94 \pm 1.03 \mathrm{~A} \mathrm{a}$ \\
\hline & Ripe, 2012 & $33.21 \pm 21.61 \mathrm{~B} \mathrm{a}$ & $53.34 \pm 6.29 \mathrm{C} \mathrm{a}$ & $23.14 \pm 2.15 \mathrm{~B} \mathrm{a}$ \\
\hline & Ripe, 2013 & $29.33 \pm 2.04 \mathrm{~A} \mathrm{ab}$ & $45.15 \pm 1.61 \mathrm{~B} \mathrm{a}$ & $20.01 \pm 2.09 \mathrm{~A} \mathrm{a}$ \\
\hline & ANOVA $p$ value & $* * *$ & $* * *$ & $* * *$ \\
\hline \multirow{7}{*}{ "Picual" } & Green, 2012 & $43.51 \pm 1.00 \mathrm{~B} \mathrm{~b}$ & $51.07 \pm 1.51 \mathrm{CD}$ a & $36.55 \pm 3.73 \mathrm{~B} \mathrm{~b}$ \\
\hline & Green, 2013 & $26.64 \pm 2.20 \mathrm{~A} \mathrm{a}$ & $41.35 \pm 1.36 \mathrm{~B} \mathrm{~b}$ & $21.89 \pm 3.24 \mathrm{~A} \mathrm{a}$ \\
\hline & Semiripe, 2012 & $28.79 \pm 0.09 \mathrm{~A} \mathrm{a}$ & $36.34 \pm 1.61 \mathrm{~A} \mathrm{a}$ & $21.06 \pm 2.51 \mathrm{~A} \mathrm{a}$ \\
\hline & Semiripe, 2013 & $39.49 \pm 2.28 \mathrm{~B} \mathrm{~b}$ & $54.48 \pm 3.94 \mathrm{D} \mathrm{c}$ & $33.06 \pm 1.84 \mathrm{~B} \mathrm{C}$ \\
\hline & Ripe, 2012 & $31.42 \pm 2.67 \mathrm{~A} \mathrm{a}$ & $44.45 \pm 4.97 \mathrm{BC} \mathrm{a}$ & $24.27 \pm 1.91 \mathrm{~A} \mathrm{a}$ \\
\hline & Ripe, 2013 & $28.89 \pm 0.72 \mathrm{~A} \mathrm{a}$ & $49.24 \pm 6.03 \mathrm{CD} \mathrm{a}$ & $19.92 \pm 0.61 \mathrm{~A} \mathrm{a}$ \\
\hline & ANOVA $p$, value & $* * *$ & $* * *$ & $* * *$ \\
\hline \multirow{6}{*}{ Significance } & Green, 2012 & $* * *$ & $* * *$ & $* *$ \\
\hline & Green, 2013 & $* * *$ & $* * *$ & $* * *$ \\
\hline & Semiripe, 2012 & N.S. & N.S. & * \\
\hline & Semiripe, 2013 & $* *$ & $* *$ & $* *$ \\
\hline & Ripe, 2012 & N.S. & N.S. & $* *$ \\
\hline & Ripe, 2013 & $*$ & $* *$ & $* *$ \\
\hline
\end{tabular}

$\overline{\mathrm{Z}}$ Data presented as mean $\pm \mathrm{SD}$ values $(n=3)$ for each sampling day followed by different uppercase letters are significantly different at $p<0.05$ on the ripening stage. ${ }^{\mathrm{Y}}$ Mean values $\pm \mathrm{SD}(n=3)$ for each ripening stage and season followed by different lowercase letters showed significant differences between cultivars at $p<0.05 .{ }^{\mathrm{X}}$ Level of significance: N.S.: not significant $(p>0.05) ;{ }^{*}$ significant at $p<0.05 ;{ }^{* *}$ significant at $p<0.01 ;{ }^{* * *}$ significant at $p<0.001$.

the three cultivars evaluated ("Cobrançosa," "Galega," and "Picual"). Hence, at the green stage, the highest content of total phenolics was found in "Cobrançosa" (50.11 and $47.05 \mathrm{mg} \mathrm{GAE} \mathrm{g}^{-1} \mathrm{dw}$ at seasons 2012 and 2013, resp.) followed by "Galega" (37.57 $\mathrm{mg} \mathrm{GAE} \mathrm{g}^{-1} \mathrm{dw}$, on average) and "Picual" (35.08 $\mathrm{mg} \mathrm{GAE} \mathrm{g}^{-1} \mathrm{dw}$, on average), 22.8 and $27.8 \%$ lower than "Cobrançosa," respectively. Concerning the content in semiripe and mature olives, no significant differences $(p>0.05)$ were observed between the three cultivars under study (Table 3). The lack of significance in the semiripe and ripe stages between cultivars can be due to the very different climatic conditions during both 2012 and 2013 seasons (Table 1), which provided wide dispersion ranges of total phenolics (Table 3 ). When comparing the kinetics of the content of total phenolics throughout the diverse ripening stages, green olives of "Cobrançosa" and "Galega" displayed significantly higher values $(p<0.001)$ than semiripe/ripe drupes by $31.4 / 29.5 \%$ and $24.8 / 16.8 \%$, respectively. Regarding Picual, the highest content of total phenols was observed for green (season 2012) and semiripe (season 2013) olives
(43.51 and $39.49 \mathrm{mg} \mathrm{GAE}^{-1} \mathrm{dw}$, resp.), while all the other samples from the same cultivar displayed similar lower levels, of around $30 \mathrm{mg} \mathrm{GAE} \mathrm{g}^{-1} \mathrm{dw}$.

The total phenolic contents, as well as the kinetics observed during on-tree ripening, were consistent with the data available in the literature, which demonstrated a significant decrease of the total phenolics throughout the maturation in diverse olive cultivars ("Arbequina" and "Cobrançosa") [18-20]. In addition, this trend was also described by Jess Tovar et al. [21], even though the differences found between semiripe and ripe stages, in that case, were not statistically significant. Moreover, these changes have been attributed to variations in the activity of hydrolytic enzymes throughout the maturation process in other research works [22].

The assessment of the content of orthodiphenols demonstrated the significant differences found between cultivars, as well as the differences due to the diverse climatic conditions in 2012 and 2013 seasons, as confirmed 
by the wide range of values recorded for these compounds (33.96-74.89 $\mathrm{mg} \mathrm{GAE} \mathrm{g}^{-1} \mathrm{dw}$ ), whilst rather homogenous values were noticed when the distinct ripening stages were compared (Table 3). In olives from "Cobrançosa" cv. the orthodiphenols concentration decreased from 74.89 and $57.62 \mathrm{mg} \mathrm{GAE} \mathrm{g}^{-1} \mathrm{dw}$ in green olives (for 2012 and 2013 seasons, resp.) to 40.95 and 49.00 (semiripe) and to 49.50 and 54.95 (ripe) $\mathrm{mg} \mathrm{GAE} \mathrm{g}^{-1} \mathrm{dw}$. On the other hand, olives of "Galega" cv. displayed the highest content of orthodiphenols in green and ripe stages ( 46.67 and $49.30 \mathrm{mg} \mathrm{GAE} \mathrm{g}^{-1} \mathrm{dw}$, on average, resp.), which surpassed the content recorded in semiripe olives by $25.8 \%$. Finally, regarding "Picual," even though some significant differences were found, the wide variation observed for each ripening stage, between the two seasons under study (2012 and 2013), did not allowed retrieving rational conclusions concerning the effect of ripening on the orthodiphenols content.

The comparison of these results with the data available in the literature (from 13.61 to $41.65 \mathrm{mg} \mathrm{GAE} \mathrm{g}^{-1}$ for the semiripe olives and from 15.84 to $40.76 \mathrm{mg} \mathrm{GAE} \mathrm{g}^{-1} \mathrm{dw}$ in the ripe stage) showed matching values of orthodiphenols $[19,20]$. In addition, this data further confirmed the significant decline of these compounds during ripening, demonstrated in two Tunisian olive tree cultivars by Brahmi et al. [23].

Apart from the evolution of orthodiphenols during ontree ripening, the study of the effect of the genetic background allowed describing noticeable differences between green olives from the three cultivars. Hence, at this stage, "Cobrançosa" olives presented the highest concentration (66.26 $\mathrm{mg} \mathrm{GAE} \mathrm{g}^{-1} \mathrm{dw}$, on average), whilst "Galega" and "Picual" drupes remained in similar lower levels (46.44 $\mathrm{mg} \mathrm{GAE} \mathrm{g}^{-1} \mathrm{dw}$, on average), suggesting that the diverse cultivars vary greatly on their capacity to synthesize phenolics. In addition, the significant differences between cultivars at the semiripe and ripe maturation stages also pointed out the different kinetics of orthodiphenols during ripening [24].

The assessment of the flavonoid contents in olive drupes showed significant variations among different cultivars and ripening stages, in agreement with the description available in the literature [13]. Thus, the highest content of flavonoids in "Cobrançosa," "Galega," and "Picual," similarly to other contents, corresponded to green olives (43.02, 32.29, and $29.22 \mathrm{mg} \mathrm{CAT} \mathrm{g}^{-1} \mathrm{dw}$, on average, resp.). When determining the average decrease of the flavonoids' content throughout ripening, relative to green drupes, a significant decrease was observed, leading to 40.3 and $33.5 \%$ lower concentrations in olives of "Cobrançosa" and "Galega," respectively. Regarding "Picual," whilst the content in semiripe and ripe olives (27.06 and $22.10 \mathrm{mg} \mathrm{CAT} \mathrm{g}^{-1} \mathrm{dw}$, on average, resp.) decreased throughout the ripening process with respect to green drupes (29.22 $\mathrm{mg} \mathrm{CAT} \mathrm{g}^{-1} \mathrm{dw}$, on average), even though these variations were not statistically significant, as observed for orthodiphenols.

With respect to differences regarding the content of flavonoids between cultivars at the same ripening stage, the highest concentration was recorded in "Cobrançosa" for the three maturations stages considered, followed by "Picual" and
"Galega" (Table 3). In addition, the content of flavonoids followed the same trend observed for total phenolics and orthodiphenols described in the literature, since a decrease was observed for "Chemlali" and "Neb Jmel" cultivars throughout the maturation process [23]. This decrease of the phenolic contents in olive fruits is probably correlated with the increased activity of the hydrolytic enzymes during ripening $[25,26]$.

3.2. Radical Scavenging Capacity In Vitro. In this study, the in vitro antioxidant activity of the olives' polyphenolic extracts was measured in vitro by four different methods: DPPH, ABTS, FRAP, and ORAC $\mathrm{FL}$ (Figure 1). Concerning $\mathrm{ABTS}^{*+}$, values recorded from olives of all three cultivars and ripening stages ranged from 51.26 to $327.78 \mathrm{mM}$ Trolox g $^{-1} \mathrm{dw}$. However, given the dispersion of the data, no significant differences were observed between the diverse samples under evaluation. On the other hand, from the results obtained concerning $\mathrm{ABTS}^{*+}$ scavenging capacity, the comparison of data from distinct seasons allowed stressing significant differences concerning either cultivar or ripening stage, namely, semiripe "Cobrançosa" and "Galega" ( $p<0.05$ and $p<0.01$, resp.). These variations could be assigned either to the different agroclimatic conditions, recorded during the seasons under comparison, or to the consequent responses to biotic stress, which seem to be especially relevant at the semiripe stage (Table 1).

When evaluating the capacity of the hydromethanolic extracts to scavenge $\mathrm{DPPH}^{\circ}$, values ranging from 96.52 to $179.90 \mathrm{mM}$ Trolox g $^{-1} \mathrm{dw}$ were observed. In this regard, the distinct cultivars assessed exhibited different trends concerning the $\mathrm{DPPH}^{\circ}$ scavenging capacity of their polyphenolic extracts (Figure 1). This fact allows emphasizing the critical impact of the genetic background on the final polyphenolic content and thus on the antioxidant activity. "Cobrançosa" olives were featured by the highest DPPH radical scavenging power at the green stage, which was significantly higher than ripe drupes (a 20.9\% lower), whilst "Galega" olives exhibited the best values at both green and ripe stages, which remained in similar levels $\left(148.96 \mathrm{mM}\right.$ Trolox g $^{-1} \mathrm{dw}$, on average). Semiripe "Galega" drupes presented 25.5\% lower values, on average, in comparison with green and ripe olives. Finally, the analysis of "Picual" fruits showed differences solely between semiripe and ripe stages (Figure 1).

In addition to the variations noticed throughout ripening, the comparison of the $\mathrm{DPPH}^{*}$ scavenging capacity between different cultivars, at matching maturation stages, allowed describing the major changes occurring in semiripe and ripe olives, whilst no significant differences were observed at the green stage. In this sense, the highest DPPH-based antiradical activity of semiripe drupes corresponded to "Picual" (151.96

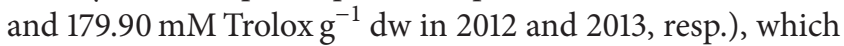
surpassed the values observed in "Cobrançosa" and "Galega" by 24.9 and $33.3 \%$, on average, respectively. On the other hand, at the ripe stage, the highest activity corresponded to "Galega" drupes' extracts, which was only significantly higher than "Cobrançosa" olives (22.0\% lower) (Figure 1). 

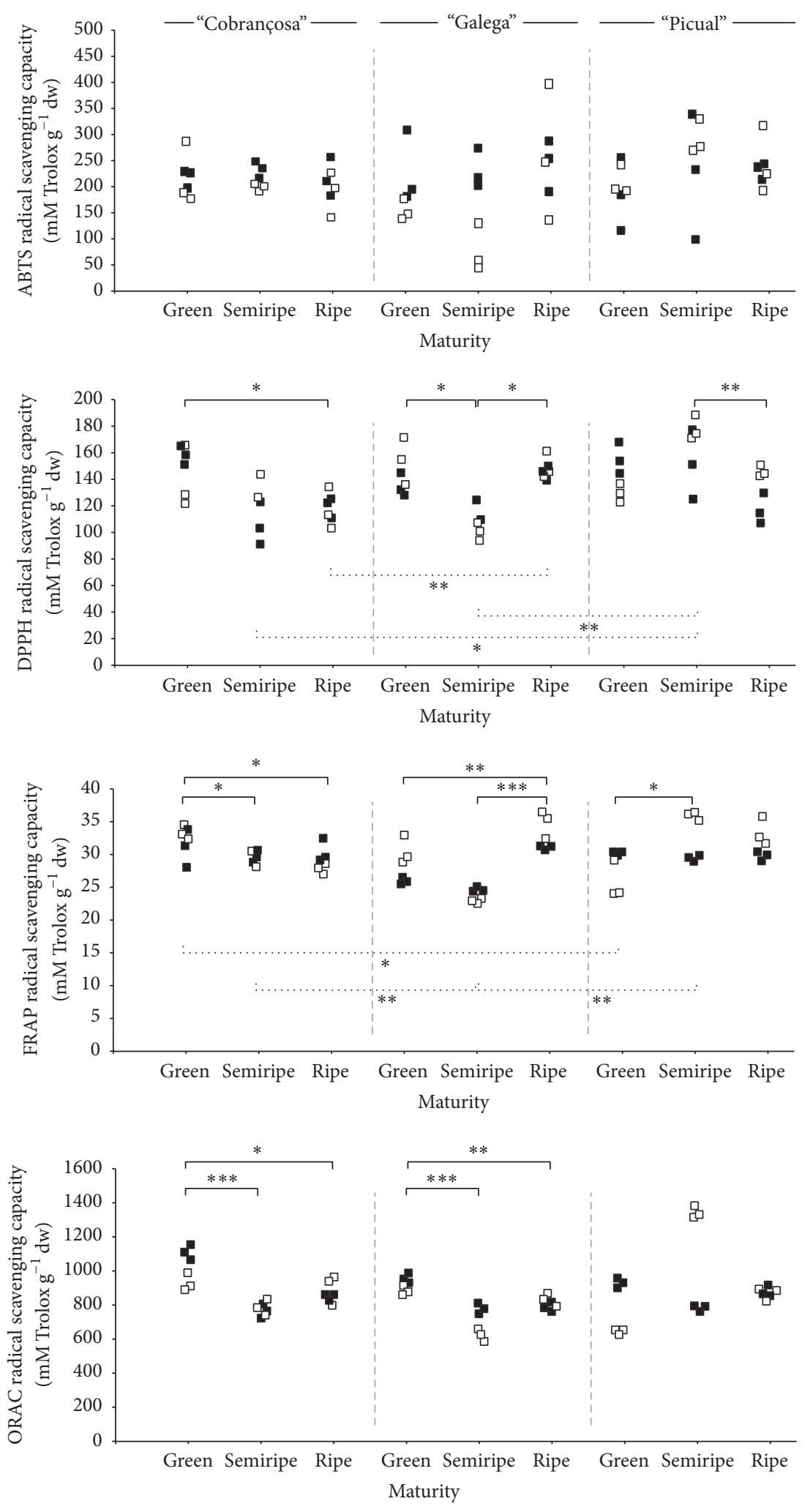

$\square 2013$

FIguRE 1: Antioxidant activity of (poly)phenolic extracts obtained from olive fruits (cultivars Cobrançosa, Galega, and Picual) in three distinct ripening stages (green, semiripe, and ripe). The dot plots compare the antioxidant activity of distinct maturity of the same cultivar as well as matching ripening stage of different cultivars. It presents data from two consecutive seasons (2012, black squares, and 2013, white

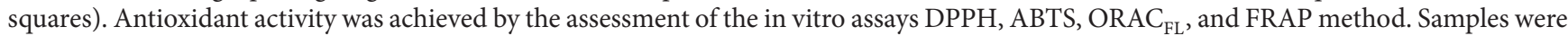
significantly different at ${ }^{*} p<0.05 ;{ }^{* *} p<0.01$; and ${ }^{* * *} p<0.001$. 

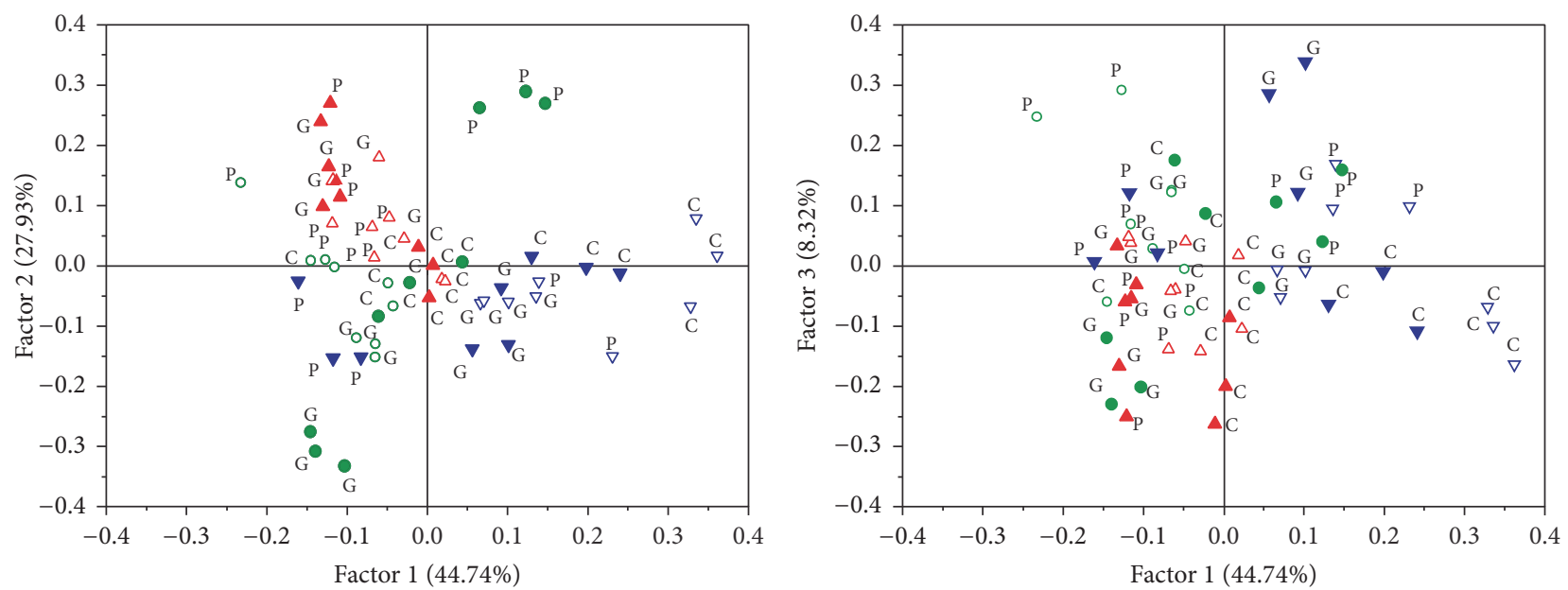

$\begin{array}{ll}\text { Ripening stage } & \\ \nabla \text { Green, 2012 } & \text { Green, 2013 } \\ \bigcirc \text { Semiripe, 2012 } & \text { Semiripe, 2013 } \\ \triangle \text { Ripe, 2012 } & \text { A Ripe, 2013 } \\ \text { Cultivar } & \\ \text { C, "Cobrançosa" } & \text { P, "Picual” } \\ \text { G, "Galega" } & \end{array}$

FIGURE 2: Score plots obtained from the PLS analysis of olives of different cultivars and ripening stage.

The evaluation of the reducing power by the FRAP method allows describing the potential of antioxidants to react with ferric tripyridyltriazine complex, forming the lowest oxidative ferrous form [27]. The evaluation of the reducing capacity showed different kinetics for each cultivar throughout ripening. The results from the FRAP method were similar to those obtained when testing the ABTS radical scavenging capacity. However, the former provided rather homogeneous and consistent results, allowing describing significant differences between cultivars and ripening stages. In this sense, a decrease of the reducing capacity of "Cobrançosa" drupes was observed in FRAP throughout the maturation stages monitored, mirroring the highest reducing capacity corresponding to green drupes (31.74 and $33.02 \mathrm{mM}$ Trolox $^{-1} \mathrm{dw}$ in 2012 and 2013, resp.). On the opposite side, "Galega" olives showed a significant increase at the ripe stage, up to 31.34 and $34.85 \mathrm{mM}^{\text {Trolox }} \mathrm{g}^{-1} \mathrm{dw}$ in 2012 and 2013, respectively, surpassing green and semiripe drupes (15.3 and $28.4 \%$ lower, on average, resp.). The same increase during ripening was observed for "Picual" olives, even though significant differences were only observed between green and semiripe stages.

Finally, the $\mathrm{ORAC}_{\mathrm{FL}}$ method allows a direct measure of hydrophilic chain-braking antioxidant activity against peroxyl radical [17]. In this connection, the values obtained for drupes by the ORAC $\mathrm{FL}_{\mathrm{F}}$ assay allowed separating samples from 2012 and 2013, contributing to a rational understanding on the effect of diverse agroclimatic conditions on the antioxidant capacity of olives. The overall $\mathrm{ORAC}_{\mathrm{FL}}$ values

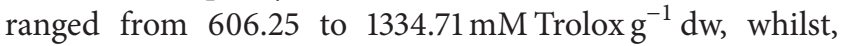
concerning the effect of ripening, the most reactive samples were green drupes of "Cobrançosa" and "Galega," which surpassed significantly the values recorded for semiripe and ripe olives. Concerning "Picual," the divergent trends observed for each season did not allow stating significant differences between ripening stages, while showing that the rather intense response of this cultivar to biotic or abiotic stresses strongly influences its ability to delete peroxyl radicals.

Despite the rather similar trend observed through the panel of antioxidant (radical scavenging and reducing capacity) methods, developed in the present work, the distinct reactivity described for each specific approach has been previously described, being assigned to their distinct mode of action, especially concerning $\mathrm{ORAC}_{\mathrm{FL}}$ (biological-like method) $[28,29]$. Nevertheless, the differential dimension of data retrieved for each method does not compromise the informative value of the distinct methods implemented. On the contrary, since the actual antioxidant activity of foodstuffs is influenced by multiple biochemical mechanisms, the assessment of the radical scavenging capacity by diverse analytical techniques allows obtaining complementary information on the real antioxidant power of olives, especially because of the complex phytochemical composition and the synergistic mechanisms occurring in polyphenolic extracts.

3.3. Chemometric Analysis. Multivariate analysis approaches have been applied to assess the maturation stage, resorting to the parameters evaluated (polyphenolic composition and antioxidant activity). Hence, unforeseen correlations between distinct samples could be highlighted from the plots of the factors' (F) scores (Figure 2, Table 3), therefore allowing the assessment of similarities between the cultivars at distinct 
ripening stages and thus correlating the differentiated susceptibilities to Colletotrichum acutatum with the phenolic contents of each cultivar. This analysis has been undertaken with resorting to the triplicates assessed for each sample.

From the analysis of the plot F1/F2, it can be seen that F1, explaining $44.7 \%$ of variance between samples, tendentiously separates ripe and green samples to negative and positive scores, respectively. Regarding F2 (explaining $27.9 \%$ of the total variance), once again, distinct trends are observed for green and ripe samples, with the former corresponding to negative scores for this factor. However, some exceptions to this trend were found, with the three replicates corresponding to green "Picual" (2013) displaying negative scores for F1, whilst three replicates of ripe "Cobrançosa," two from 2012 and one from 2013, displayed positive scores for F2 (Figure 2).

Furthermore, specific trends concerning the distinct cultivars can be immediately regarded, with the "Cobrançosa" semiripe and ripe samples lying on the centre of the plot, while the green samples of this cultivar present the highest scores for F1 (Figure 2). Regarding F2, this factor separates semiripe samples of "Picual" and "Galega," to positive and negative scores, respectively, while, concerning Factor 1, the "Picual" (2013) samples in this ripening stage present similar values to the green "Galega" samples.

Hence, concerning the 2013 crop, the "Galega" semiripe samples are found near the "Picual" green olives, while both samples present negative scores for F1, similarly to the ripe samples of both years (Figure 2). In 2012, similar trends are observed, with "Picual" and "Galega" samples presenting negative and positive scores for F2, respectively, while the latter cultivar presented negative scores for Fl, contrasting with the 2013 samples, which displayed positive scores. Moreover, regarding 2012, the green "Cobrançosa" samples displayed the highest scores for F1, amongst all samples (Figure 2).

Since F1 is mainly determined by the phenolic content (total phenolics, orthodiphenols, and flavonoids) and F2 by the antioxidant activity (ABTS, DPPH, FRAP, and ORAC $\mathrm{FL}_{\mathrm{FL}}$ ), the discrimination between samples can be understood at the light of these parameters. Hence, concerning the green samples from "Cobrançosa," which fall within the positive range of $\mathrm{Fl}$, these were featured by the highest contents of total phenolics and flavonoids (Table 3), whilst the negative scores for F2 corresponding to the green drupes of "Galega" and "Picual" might be due to the below-average activities displayed by these samples in the FRAP assay (Figure 1).

Concerning F1, the 2013 "Picual" green sample, with negative scores for all replicates, presented lower quantities of total phenols and flavonoids, in comparison with green drupes of the same variety from 2012 and those of "Cobrançosa" and "Galega" from both seasons. Thus, these "Picual" samples (season 2013) were found on the left side of the plot, alongside the ripe samples, characterized by lower contents of these compounds (Figure 2).

Concerning the samples at semiripe stage, those from 2013 season were generally placed in the diagonal of the plot, whilst the samples from 2012 were tendentiously found in the left bottom quadrant (Figure 2). Since the multivariate analysis has taken the maturation stage as dependent variable, this distribution is logical, whereas the trend observed for samples collected in the 2012 season was caused by their content of total phenolics and flavonoids, as previously observed for green "Picual" samples from 2013 (Figure 2, Table 3). Actually, "Galega" semiripe drupes (season 2013) presented a lower content of total phenolics, flavonoids, and orthodiphenols, being near the samples from 2012, whilst olives from "Picual" corresponding to season 2013 presented higher quantities, thus being in the opposite quadrant. The positioning of all the semiripe samples of "Cobrançosa" in the centre of the plot is due to their similar quantity of flavonoids and balance between lower quantity of total phenolics and higher content of orthodiphenols displayed by the drupes of the 2013 season, with respect to those produced in 2012 (Figure 2, Table 3).

Regarding F2, which also contributed to the separation between the semiripe samples produced in 2013, this factor is mainly weighted by the diverse measurements providing information on the antioxidant activity (Table 3 ). Thus, the high positive scores of "Picual" olives produced in 2013 were mainly due to the FRAP and $\mathrm{ORAC}_{\mathrm{FL}}$ results, with respect to not only the semiripe samples assessed from other cultivars, but also the same cultivar at matching ripening stage in season 2012 (Figures 1 and 2). In the opposite direction, semiripe "Galega" samples, from 2013, displayed the highest negative scores for F2, amongst all samples, which seem to be due to the low antioxidant activity registered for this sample (mainly through the ABTS and FRAP techniques) (Figure 1).

From the multivariate analysis, additional factors were extracted. Among these, $\mathrm{F} 3$ accounts for $8.3 \%$ of the variance between samples. Hence, it can be pointed that the F1/F3 plot, depicted in Figure 2, separates the green "Cobrançosa" samples to positive scores of F1, while these samples were separated from green "Picual" and "Galega" cultivar samples through Factor 3, these cultivars presenting negative and positive scores, respectively. Furthermore, some of the replicates of "Cobrançosa" samples, corresponding to the ripe stage, were scattered to the same quadrant. The separation of the green samples of "Cobrançosa," with respect to the other cultivars was due to their higher content of orthodiphenols, since this parameter was preponderant for F3 (Table 3).

In addition, for "Picual" semiripe samples, corresponding to the 2012 season, the increase of the DPPH values during this ripening stage was identified as the most relevant parameter for the discrimination. Meanwhile, "Galega" semiripe olives (season 2013), for which a descent in the DPPH and ABTS, besides orthodiphenols values, is observed, presented negative scores for F3, being near the "Cobrançosa" samples from the same year (Figure 2, Table 3). Concerning the evaluating of the semiripe samples from the other cultivars, no specific trend was identified with respect to $\mathrm{F} 3$, which is due to the variability observed between the diverse cultivars at this stage. Moreover, "Picual" semiripe drupes corresponding to season 2013 were only separated from the others in the same ripening stage, through $\mathrm{Fl}$, similarly to the deviation observed for green "Picual" olives from season 2013, also due to this factor (Figures 1 and 2, Table 3).

Summarizing, concerning the evaluation of olives produced in 2012, the three cultivars followed rather similar 
phenolic kinetics and antiradical activity changes throughout maturation, while in 2013 clear deviations were stated for "Picual" drupes phenolic composition during ripening. Actually, in 2013, this cultivar started the maturation process presenting distinct features, with respect to 2012, and developing off-trend in the semiripe stage. Concerning "Galega," the semiripe olives of both years were found near the ripe samples of all the cultivars, concerning F1, which reflects their matching phenolic contents, through presenting negative scores concerning F2, due to a weaker antioxidant activity with respect to the ripe olives from all cultivars, despite the similar contents (Figures 1 and 2). If the distinct agroclimatic conditions observed in the two years are considered (Table 1), it can be elated that distinct cultivars respond differently to the agroclimatic factors, while the maturation process in "Cobrançosa" seems to be rather insensitive to these conditions. At the ripe stage, all the cultivars have shown rather similar contents, whereas the "Picual" cultivar displayed divergent developments in the two distinct seasons, mainly concerning the semiripe stage, thus reflecting a rather pronounced response to distinct external stresses.

Therefore, since it is well known that the resistance to C. acutatum diminishes throughout the maturation process [9], while these three cultivars have been assessed on their differentiated responses $[10,19]$, sturdy evidences, concerning the relation between phenolic contents and susceptibility, can now be pointed. Hence, since the three cultivars present similar behaviours in the ripe stage (Figures 1 and 2; Table 3), it can be assumed that these contents will not be preponderant at this stage, whereas the different behaviours observed between the distinct cultivars at the semiripe stage point to the prominence of the phenolic response at this phase for the prevention of this infection.

This is clearly supported by the characterization of "Galega" semiripe samples, which show similar behaviour to the all cultivars in the ripe stage, corresponding to the highest susceptibility to C. acutatum (Figures 1 and 2). Moreover, a descent in the antioxidant activity of this cultivar in the semiripe stage is clearly visible, whereas, for "Cobrançosa" and "Picual," this activity is maintained or increased at this maturation phase, which is also dependent on the harvest year, reflecting the increased response of the latter cultivar to biotic or abiotic stresses (Figure 1).

\section{Conclusions}

The data obtained evidenced the critical influence of the ontree ripening stage, concerning the final content of bioactive polyphenols and the radical scavenging capacity, of olives from three different cultivars during two consecutive seasons (2012 and 2013). Nonetheless, the decrease of the contents of total phenolics, orthodiphenols, and flavonoids, recorded in olives during ripening, did not entail a direct reduction of the antioxidant capacity. This fact suggests that the final radical scavenging capacity is dependent not only on the content of total phenolics, orthodiphenols, and/or flavonoids, but also on the variations of individual phenolics during the maturation process, which merit to be further evaluated in order to identify those compounds that can be responsible for the healthy features of this foodstuff.

Moreover, the multivariate analysis undertaken showed that the distinct maturation stages can be discriminated through the parameters assessed, while being observed that the cultivars respond differently to distinct agroclimatic factors, during the maturation process. Furthermore, the application of multivariate analysis to the parameters assessed throughout the ripening process in the three cultivars seems to point that the phenolic contents during semiripe stage are crucial for the resistance to "Colletotrichum acutatum," since "Picual" displayed the most pronounced response, while, on the contrary, "Galega," the most susceptible cultivar, presented a descent in this stage, whereas in ripe fruits all three cultivars displayed similar contents.

\section{Competing Interests}

The authors declare no conflict of interests.

\section{Acknowledgments}

This work was supported by national funds from FCT, Portuguese Foundation for Science and Technology, under the Projects UID/AGR/04033/2013 and POCI-01-0145-FEDER006958. This work was also supported by the Project Ph.D. Grant SFRH/BD/78013/2011 from the Fundação para a Ciência e Tecnologia to Irene Gouvinhas. Raúl DomínguezPerles was supported by a Postdoctoral contract (SaavedraFajardo 20024/SF/16) from the Agency for Science and Technology of the Región de Murcia (Spain). Nelson Machado kindly acknowledges a postdoctoral research grant from the Centre for the Research and Technology of Agro-Environmental and Biological Sciences, with the reference BI/CITAB/UTAD/QUI/2015. Amadeo GironésVilaplana also thanks the Spanish Ministry of Economy and Competitiveness for the Juan de la Cierva Postdoctoral Grant (Reference FJCI-2014-19956).

\section{References}

[1] A. Trichopoulou, T. Costacou, C. Bamia, and D. Trichopoulos, "Adherence to a Mediterranean diet and survival in a Greek population," The New England Journal of Medicine, vol. 348, no. 26, pp. 2599-2608, 2003.

[2] K. T. B. Knoops, L. C. P. G. M. De Groot, D. Kromhout et al., "Mediterranean diet, lifestyle factors, and 10-year mortality in elderly European men and women: the HALE project," Journal of the American Medical Association, vol. 292, no. 12, pp. 1433$1439,2004$.

[3] INE, I.P. Estatísticas Agrícolas 2013 Lisboa Portugal, 2013, https://www.ine.pt/.

[4] R. Ghanbari, F. Anwar, K. M. Alkharfy, A.-H. Gilani, and N. Saari, "Valuable nutrients and functional bioactives in different parts of olive (Olea europaea L.) - a review," International journal of molecular sciences, vol. 13, no. 3, pp. 3291-3340, 2012.

[5] M.-I. Covas, "Bioactive effects of olive oil phenolic compounds in humans: reduction of heart disease factors and oxidative 
damage," Inflammopharmacology, vol. 16, no. 5, pp. 216-218, 2008.

[6] A. I. Cordeiro, J. F. Sanchez-Sevilla, M. C. Alvarez-Tinaut, and M. C. Gómez-Jimenez, "Genetic diversity assessment in Portugal accessions of Olea europaea by RAPD markers," Biologia Plantarum, vol. 52, no. 4, pp. 642-647, 2008.

[7] F. Peres, H. H. Jeleń, M. M. Majcher, M. Arraias, L. L. Martins, and S. Ferreira-Dias, "Characterization of aroma compounds in Portuguese extra virgin olive oils from Galega Vulgar and Cobrançosa cultivars using GC-O and GC × GC-ToFMS," Food Research International, vol. 54, no. 2, pp. 1979-1986, 2013.

[8] S. Gomes, P. Prieto, P. Martins-Lopes, T. Carvalho, A. Martin, and H. Guedes-Pinto, "Development of Colletotrichum acutatum on tolerant and susceptible Olea europaea L. cultivars: a microscopic analysis," Mycopathologia, vol. 168, no. 4, pp. 203211, 2009.

[9] J. Moral and A. Trapero, "Assessing the susceptibility of olive cultivars to anthracnose caused by Colletotrichum acutatum," Plant Disease, vol. 93, no. 10, pp. 1028-1036, 2009.

[10] I. Gouvinhas, N. Machado, A. Gironés-Vilaplana et al., "Sorting out the value of spectroscopic tools to assess the Colletotrichum acutatum impact in olive cultivars with different susceptibilities," Journal of Chemometrics, vol. 30, no. 9, pp. 548-558, 2016.

[11] M. Uceda and M. Hermoso, "La calidad del aceite de oliva," in El Cultivo del Olivo, D. Barranco, R. Fernàndez-Escobar, and L. Rallo, Eds., pp. 547-572, Junta de Andalucia Ediciones MundiPrensa, Madrid, Spain, 1998.

[12] M. Machado, C. Felizardo, A. A. Fernandes-Silva, F. M. Nunes, and A. Barros, "Polyphenolic compounds, antioxidant activity and L-phenylalanine ammonia-lyase activity during ripening of olive cv. 'Cobrançosa' under different irrigation regimes," Food Research International, vol. 51, no. 1, pp. 412-421, 2013.

[13] A. I. Barros, I. Freire, B. Gonçalves et al., "Evaluation of chemical and phenotypic changes in Blanqueta, Cobrançosa, and Galega during olive fruits ripening," CYTA - Journal of Food, vol. 11, no. 2, pp. 136-141, 2013.

[14] R. Mateos, J. L. Espartero, M. Trujillo et al., "Determination of phenols, flavones, and lignans in virgin olive oils by solid-phase extraction and high-performance liquid chromatography with diode array ultraviolet detection," Journal of Agricultural and Food Chemistry, vol. 49, no. 5, pp. 2185-2192, 2001.

[15] J. Zhishen, T. Mengcheng, and W. Jianming, "The determination of flavonoid contents in mulberry and their scavenging effects on superoxide radicals," Food Chemistry, vol. 64, no. 4, pp. 555$559,1999$.

[16] P. Mena, C. García-Viguera, J. Navarro-Rico et al., "Phytochemical characterisation for industrial use of pomegranate (Punica granatum L.) cultivars grown in Spain," Journal of the Science of Food and Agriculture, vol. 91, no. 10, pp. 1893-1906, 2011.

[17] B. Ou, M. Hampsch-Woodill, and R. L. Prior, "Development and validation of an improved oxygen radical absorbance capacity assay using fluorescein as the fluorescent probe," Journal of Agricultural and Food Chemistry, vol. 49, no. 10, pp. 4619-4626, 2001.

[18] R. Fernandez-Orozco, M. Roca, B. Gandul-Rojas, and L. Gallardo-Guerrero, "DPPH-scavenging capacity of chloroplastic pigments and phenolic compounds of olive fruits (cv. Arbequina) during ripening," Journal of Food Composition and Analysis, vol. 24, no. 6, pp. 858-864, 2011.

[19] A. Sousa, R. Malheiro, S. Casal, A. Bento, and J. A. Pereira, "Antioxidant activity and phenolic composition of $\mathrm{Cv}$.
Cobrançosa olives affected through the maturation process," Journal of Functional Foods, vol. 11, pp. 20-29, 2014.

[20] C. Sousa, I. Gouvinhas, D. Barreira et al., "'Cobrançosa' olive oil and drupe: chemical composition at two ripening stages," JAOCS, Journal of the American Oil Chemists' Society, vol. 91, no. 4, pp. 599-611, 2014.

[21] M. Jess Tovar, M. Paz Romero, J. Girona, and M. Jos Motilva, "L-phenylalanine ammonia-lyase activity and concentration of phenolics in developing olive (Olea europaea L. cv Arbequina) fruit grown under different irrigation regimes," Journal of the Science of Food and Agriculture, vol. 82, no. 8, pp. 892-898, 2002.

[22] M.-J. Amiot, A. Fleuriet, and J.-J. Macheix, "Importance and evolution of phenolic compounds in olive during growth and maturation," Journal of Agricultural and Food Chemistry, vol. 34, no. 5, pp. 823-826, 1986.

[23] F. Brahmi, B. Mechri, M. Dhibi, and M. Hammami, "Variations in phenolic compounds and antiradical scavenging activity of Olea europaea leaves and fruits extracts collected in two different seasons," Industrial Crops and Products, vol. 49, pp. 256-264, 2013.

[24] A. F. Vinha, F. Ferreres, B. M. Silva et al., "Phenolic profiles of Portuguese olive fruits (Olea europaea L.): influences of cultivar and geographical origin," Food Chemistry, vol. 89, no. 4, pp. 561$568,2005$.

[25] R. H. Hbaieb, F. Kotti, R. García-Rodríguez, M. Gargouri, C. Sanz, and A. G. Pérez, "Monitoring endogenous enzymes during olive fruit ripening and storage: correlation with virgin olive oil phenolic profiles," Food Chemistry, vol. 174, pp. 240247, 2015.

[26] I. Gouvinhas, J. M. M. M. de Almeida, T. Carvalho, N. Machado, and A. I. R. N. A. Barros, "Discrimination and characterisation of extra virgin olive oils from three cultivars in different maturation stages using Fourier transform infrared spectroscopy in tandem with chemometrics," Food Chemistry, vol. 174, pp. 226232, 2015

[27] I. F. F. Benzie and J. J. Strain, "The ferric reducing ability of plasma (FRAP) as a measure of 'antioxidant power': the FRAP assay," Analytical Biochemistry, vol. 239, no. 1, pp. 70-76, 1996.

[28] A. Gironés-Vilaplana, D. A. Moreno, and C. García-Viguera, "Phytochemistry and biological activity of Spanish Citrus fruits," Food \& Function, vol. 5, no. 4, pp. 764-772, 2014.

[29] A. Gironés-Vilaplana, N. Baenas, D. Villaño, H. Speisky, C. García-Viguera, and D. A. Moreno, "Evaluation of LatinAmerican fruits rich in phytochemicals with biological effects," Journal of Functional Foods, vol. 7, no. 1, pp. 599-608, 2014. 

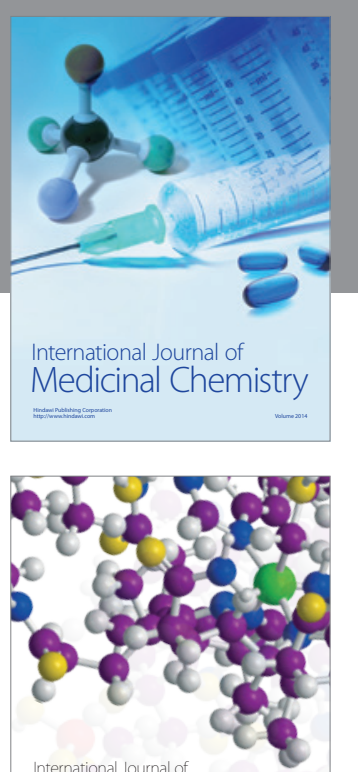

Carbohydrate Chemistry

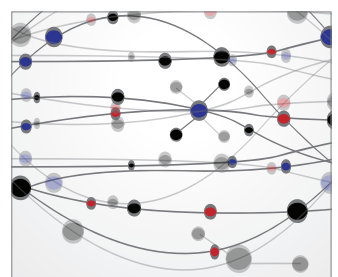

The Scientific World Journal
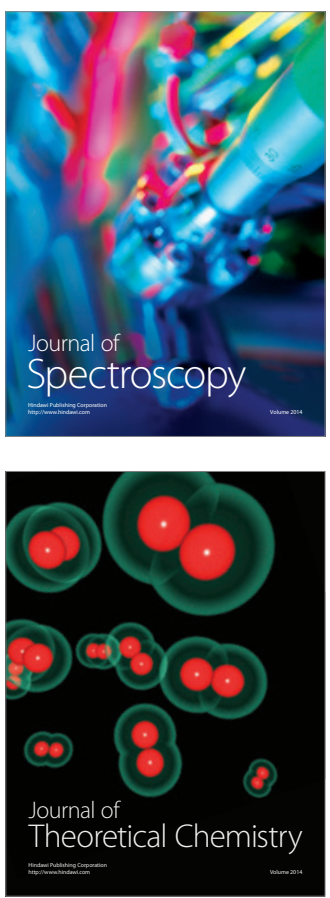
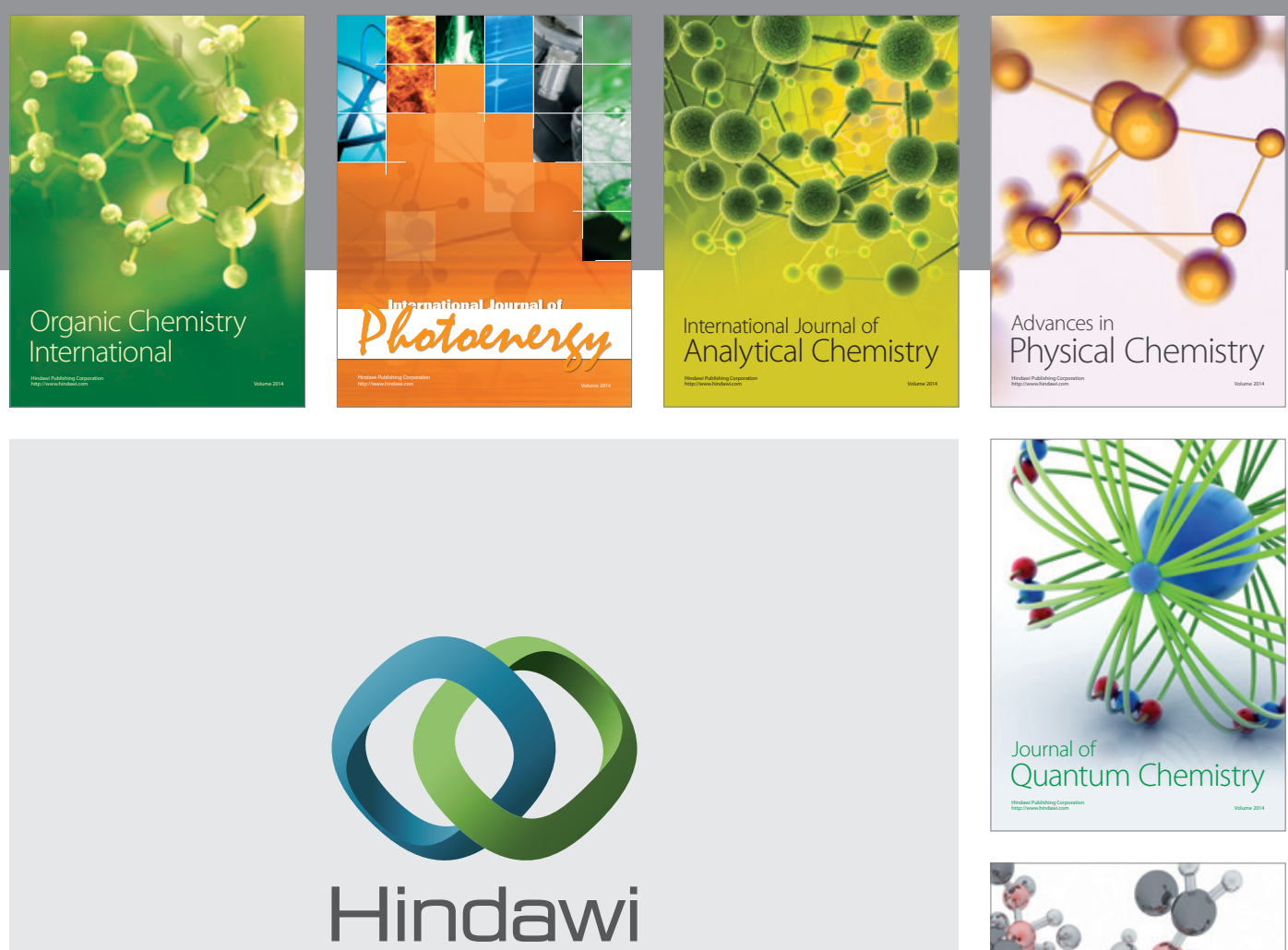

Submit your manuscripts at

https://www.hindawi.com

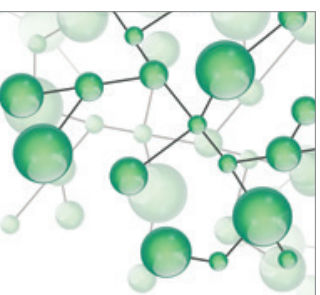

International Journal of

Inorganic Chemistry
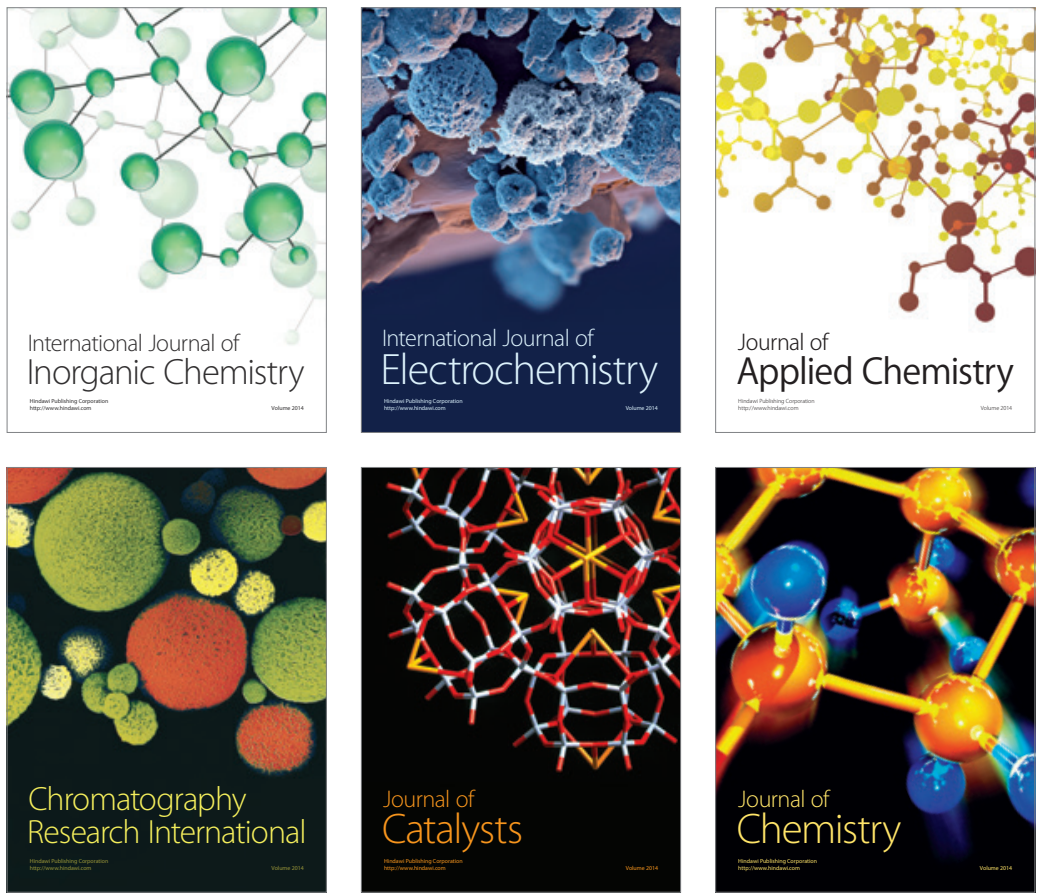

Journal of

Applied Chemistry
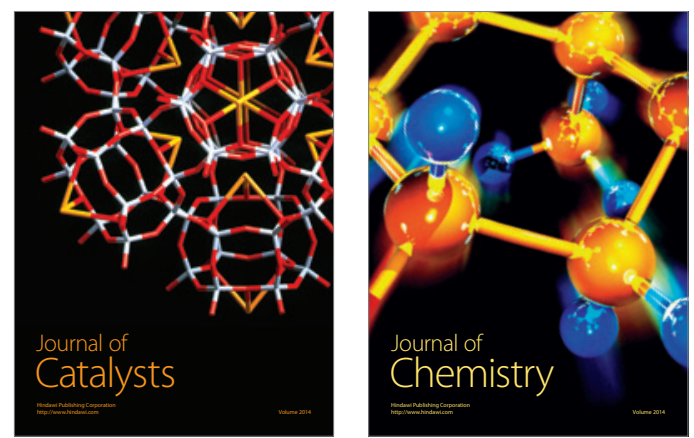
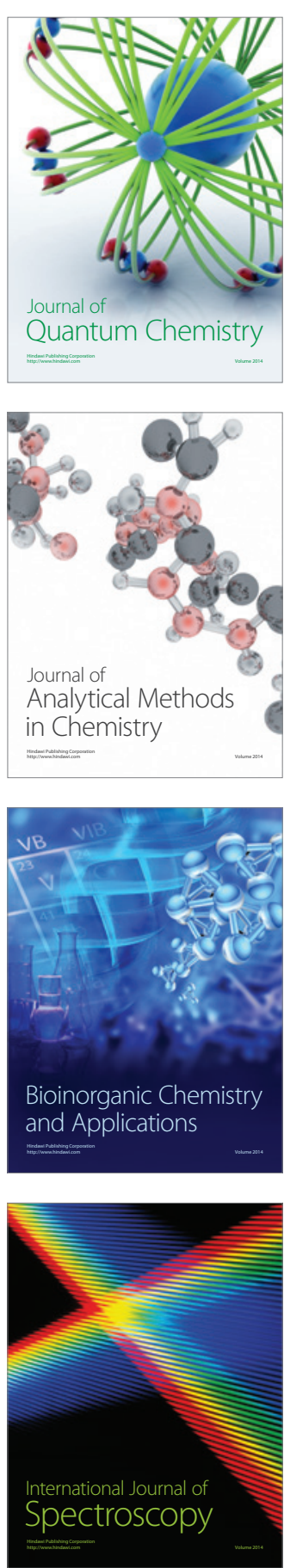